\title{
DISTRIBUIÇÃO GEOGRÁFICA E DIVERSIDADE VARIETAL DE FRUTÍFERAS E NOZES DE CLIMA TEMPERADO NO ESTADO DE SÃO PAULO ${ }^{1}$
}

\author{
WILSON BARBOSA ${ }^{2,7}$, CELSO VALDEVINO POMMER ${ }^{3,7}$, MARIÂNGELA DRUGOVICK RIBEIRO ${ }^{4}$, RENATO FERRAZ \\ DE ARRUDA VEIGA ${ }^{5}$, ANTONIO ALBERTO COSTA ${ }^{6}$
}

\begin{abstract}
RESUMO - Pesquisaram-se, de 1998 a 2002, os locais e as áreas de cultivo, o número de plantas e as principais espécies e cultivares comerciais de frutíferas e nozes de clima temperado do Estado de São Paulo. Para tanto, analisaram-se os dados do Projeto LUPA (Levantamento Censitário de Unidades de Produção Agrícola do Estado de São Paulo) e de consultas aos fruticultores de diversas regiões paulistas. Verificou-se a existência de 6 famílias botânicas, 11 gêneros e 12 principais espécies de frutíferas e uma de noz de clima temperado. São elas, em ordem decrescente do número de plantas: videira rústica, videira fina, pessegueiro (incluindo nectarineira), figueira, caquizeiro, nogueira-macadâmia, macieira, ameixeira, pereira européia, pereira asiática, nespereira, quivizeiro e marmeleiro, sendo as duas primeiras responsáveis por $51 \%$ de toda a área ocupada com as referidas culturas de clima temperado. Constatou-se que esse segmento da fruticultura está sendo praticado em 9.510 propriedades de $65 \%$ dos municípios paulistas, englobando todas as 40 regionais agrícolas da CATI (Coordenadoria de Assistência Técnica e Integral), existentes no Estado. A videira e a pereira foram as únicas culturas que apresentaram mais de uma espécie botânica sendo cultivada comercialmente. Foram detectadas 53 principais cultivares, sendo a cultura do pessegueiro responsável pela maior fonte de diversidade varietal. Considerando as épocas de colheita das frutíferas e nozes pesquisadas, observaram-se produções de frutos em todos os meses do ano, especialmente entre outubro e abril. Registraram-se novos e importantes nichos de cultivo nas regiões de Jales, Presidente Prudente, Barretos e Jaú, com predominância das uvas finas, das pêras asiáticas, dos pêssegos adaptados e da nogueira-macadâmia, respectivamente.
\end{abstract}

Termos para indexação: fruticultura de clima temperado, espécie, cultivar, produção de frutos, município.

\section{GEOGRAPHIC DISTRIBUTION AND VARIETAL DIVERSITY OF TEMPERATE FRUITS AND NUTS IN SÃO PAULO STATE, BRAZIL}

\begin{abstract}
During the period of 1998 to 2002 it was investigated, through the LUPA census (Levantamento Censitário de Unidades de Produção Agrícola do Estado de São Paulo), the locals and cultivated areas, the plant quantities and main species of temperate fruits and nuts in São Paulo State, Brazil. Fruit growers from all regions of the State were consulted about commercial cultivars used. The data showed 6 botanical families, 11 genus and 12 main temperate fruit and one nut species: rustic grape, fine grape, peach (and nectarine), fig, persimmon, macadamia nut, apple, japanese plum, European pear, Asiatic pear, loquat, kiwi and quince trees. The grapes are planted on $51 \%$ of the total area occupied by temperate fruits and nuts, 11,9 thousand ha. A total of 9,510 of temperate fruit growers were recorded in $65 \%$ of all the municipality of the State. Only the grape and pear showed more than one botanical species commercially cultivated. Fifty three principal cultivars were detected in commercial cultivation, most of them in peach trees. Considering the twelve main species, the fruit harvest occurs during all months of the year. It was recorded new important fruit crop niches at Jales, Presidente Prudente, Barretos and Jaú regions, respectively, with emphasis to fine grapes, asiatic pears, adapted peaches and macadamia nuts.
\end{abstract}

Index terms: temperate fruit species, cultivar, fruit grower, genetical diversity, harvest

A fruticultura de clima temperado paulista tem-se caracterizado, nas últimas décadas, por significativa ampliação regional e renovação estrutural e varietal. Em moldes comerciais, essa fruticultura deixou de ser praticada somente em áreas serranas e em municípios próximos da capital, deslocando-se para outras regiões subtropicais e tropicais do interior, muitas vezes desprovidas de temperaturas hibernais baixas (Pedro Junior et al., 1979; Barbosa et al., 1990b).

O cultivo comercial de frutíferas temperadas distribui-se por diversas regiões paulistas, graças às ações de programas locais de pesquisas, principalmente de melhoramento genético, de introdução e avaliação de cultivares e de sistemas de cultivo (Santos Neto, 1955; Rigitano, 1968; Programa Integrado de Pesquisa, 1985; Campo Dall'Orto et al. 1986; Ojima et al., 1988; Pommer, 1993; Barbosa et al., 1997b). Os resultados alcançados têm estimulado os fruticultores a investirem nesse mercado, popularizando culturas como videira, frutíferas de caroço e nogueira-macadâmia. Com isso, muitos pomares de frutas de clima temperado foram instalados em regiões novas, pouco pesquisadas quanto à adaptação climática e cultural.

Assim sendo, é oportuno realizar um mapeamento desses novos locais incomuns às culturas, bem como identificar as cultivares mais usuais nas diversas regiões frutícolas. De posse desses dados, novas pesquisas locais podem ser programadas, fornecendo desta forma maio- res subsídios técnico-científicos e econômicos à fruticultura regional paulista.

Objetivando verificar a atual distribuição geográfica e caracterizar a quantidade e diversidade de espécies e cultivares comerciais de frutíferas e nozes de clima temperado existentes no Estado de São Paulo, realizou-se o presente trabalho.

Efetuou-se o levantamento da distribuição geográfica e da quantidade e diversidade de frutíferas e nozes de clima temperado através de consultas aos dados do último censo agropecuário do Estado de São Paulo, denominado Projeto LUPA (Pino et al., 1997). O referido censo foi realizado em 1995/96 e atualizado parcialmente em 1998. Para cada tipo de frutífera temperada pesquisaram-se neste trabalho: regiões e municípios produtores, área de cultivo, quantidade de plantas, bem como o número de propriedades rurais envolvidas.

Para o conhecimento das principais cultivares e espécies presentes na fruticultura de clima temperado, realizou-se, de 1998 a 2002, um levantamento entre os fruticultores das principais regiões frutícolas paulistas. Para tanto, foram enviados 165 questionários com informações sobre as principais cultivares de frutíferas e nozes de clima temperado mais plantadas na propriedade com fins comerciais. Foram enviados de 12 a 20 questionários para cada tipo de fruticultor ou especialidade frutífera. Optou-se em classificar, por frutífera, somente as cultivares que foram

\footnotetext{
${ }^{1}$ (Trabalho 132/2002). Recebido: 04/06/2002. Aceito para publicação: 30/04/2003. Trabalho integrante da pesquisa IAC 1.1993025-14: "Caracterização da biodiversidade e das espécies, cultivares e seleções de frutíferas de clima temperado do Estado de São Paulo".

${ }^{2}$ Biológo, MSc., Pesquisador Científico (PqC), do Centro Experimental Central (CEC), do Instituto Agronômico (IAC). Caixa Postal 28, 13001-970, Campinas, SP. Fone: 193241-5188 E-mail: wbarbosa@iac.sp.gov.br .

${ }^{3}$ Eng. Agr., Dr., PqC, Capta-Frutas, IAC. Fone: $193241-9910$ E-mail: pommer@ @iac.br.

${ }^{4}$ An. Sist., BS., CATI. Caixa Postal 960, 13073-001 Campinas, SP. Fone: 19 3743-3700.

${ }^{5}$ Eng. Agr., Dr., PqC, CEC, IAC. Fone: 193241-5188 E-mail: veiga @ iac.br.

${ }^{6}$ Eng. Agr., Dr., PqC, CEC, IAC. Fone: 19 3241-5188 E-mail: costa@ iac.br.

${ }^{7}$ Bolsista do CNPq
} 
citadas em mais de 50\% dos questionários. As demais cultivares, no entanto, foram registradas e apresentadas no trabalho, objetivando o conhecimento da diversidade varietal, bem como as possíveis tendências do mercado frutícola do Estado de São Paulo. Nesta pesquisa, mesmo que relatadas pelos fruticultores, não foram consideradas a quantidade de plantas por cultivar, nem o material existente em coleções particulares.

Pela análise dos dados do LUPA, verificou-se a existência de 6 famílias botânicas, 11 gêneros e 12 principais espécies de frutíferas e uma de noz de clima temperado sendo cultivadas no Estado de São Paulo. São elas: videira rústica (Vitis labrusca L. e híbridos naturais V. vinifera $\mathrm{x} V$. labrusca), videira fina (Vitis vinifera $\mathrm{L}$.), pessegueiro (Prunus persica $\mathrm{L}$. Batch), incluindo a nectarineira (P. persica L. Batch, variedade nucipersica), figueira (Ficus carica L.), caquizeiro (Diospyrus kaki L. f.), macieira (Malus domestica Borkh), ameixeira (Prunus salicina Lindl.), pereira européia (Pyrus communis L.), pereira asiática (P. serotina Reidher), quivizeiro (Actinidia deliciosa [A. Chev.] C.F. Liang \& A. R. Fergunson), marmeleiro (Cydonia oblonga Mill.), além da nogueira-macadâmia (Macadamia integrifolia Maid. \& Bet.)

Por considerar os dados inconsistentes, não serão apresentados resultados obtidos com as seguintes frutíferas: abricoteiro (Prunus armeniaca L.), amoreira (Rubus sp.), cerejeira (P. avium L.), framboezeira (Rubus sp.), nogueira-pecã (Carya illinoensis L.) e umezeiro (Prunus mume Sieb. \& Zucc.). Nas Tabelas 1 e 2, também não foram incluídos dados do quivizeiro e do marmeleiro, devido ao baixo número de informações obtidas com os fruticultores regionais.

Verificou-se que, no Estado de São Paulo, as frutíferas lenhosas de clima temperado estão sendo cultivadas comercialmente em 9.510 propriedades e em $65 \%$ dos 642 municípios pesquisados. Essa fruticultura foi detectada em $100 \%$ das 40 regionais agrícolas existentes no Estado de São Paulo, demonstrando a grande expansão territorial ocorrida, principalmente durante as últimas duas décadas (Figura 1).

Observou-se que cada espécie frutífera possui um pólo geográfico principal, porém não necessariamente único. Isso ficou mais evidente em nível de cultivar, pela grande diversidade genética e adaptação climática, sendo o pessegueiro exemplo bem marcante. Encontram-se expressivos cultivos de pessegueiro desde locais ao norte, centro-leste até o sudoeste do Estado. Na Figura 1 estão indicados os principais pólos de frutíferas temperadas do Estado de São Paulo.

Foram recebidos 127 questionários, ou seja, $77 \%$ do total enviado, dos quais foi possível classificar até dez principais cultivares comerciais por frutífera, ou seja, aquelas citadas em mais de 50\% das consultas. Ao todo, foram consideradas 53 principais cultivares sendo ex- ploradas economicamente nas 127 propriedades pesquisadas, exceto para quivi e marmelo (Tabela 2). No texto, porém, são apresentadas algumas outras cultivares citadas entre 30 e $50 \%$ dos questionários.

Pelos dados do LUPA, evidenciou-se que a videira é, significativamente, a frutífera de clima temperado mais cultivada no Estado de São Paulo. Registrou-se a existência de 41,2 milhões de videiras cultivadas em 11,9 mil hectares de 38 regionais agrícolas, constituindo-se numa das frutíferas mais cosmopolitas do Estado (Tabela 1). Para a uva rústica, Jundiaí, Indaiatuba e Itupeva são os municípios que lideram, com 9,9; 5,4 e 4,7 milhões de plantas respectivamente. Para uvas finas, São Miguel Arcanjo e Pilar do Sul são os municípios com o maior número de plantas cultivadas. Palmeira D’Oeste, Jales e Urânia cultivam entre 100 e 200 mil plantas do tipo uva fina. Ao todo, verificou-se a presença de 4,3 e 36,9 mil videiras finas e rústicas de mesa, respectivamente, mostrando aumento de cerca de $10 \%$ em relação ao número de plantas existentes no início da década de 80 (Programa Paulista de Fruticultura de Clima Temperado, 1983). Entre as uvas rústicas, as principais cultivares-copa mais citadas foram: 'Niagara Rosada' (mutação somática de Niagara branca, original), híbrido natural entre as espécies Vitis labrusca L. e V. vinifera L., 'Niagara Branca' e 'Isabel', da espécie americana Vitis labrusca L., sendo as mais cultivadas na região de Campinas, cujas colheitas ocorrem desde dezembro até março (Pommer et al., 1998). Entre as uvas finas, as mais citadas foram: 'Itália', 'Rubi', 'Benitaka', 'Redglobe', 'Red Meire', 'Centennial Seedless', 'Brasil'; 'Patrícia' e 'Máximo'. Tratam-se das cultivares mais plantadas na região de Jales, no noroeste, e em São Miguel Arcanjo, no sudoeste, pertencentes originalmente à espécie européia $V$. vinifera L. ou simples mutações somáticas ('Rubi', 'Benitaka', 'Brasil') ou ainda híbridos complexos ('Patrícia' e 'Máximo'). Evidenciou-se o caráter familiar na exploração vitícola, devido ao elevado número de pequenas áreas cultivadas. Respectivamente, para uvas finas e rústicas, foram encontrados cultivos de até 2 ha em 105 e 110 municípios e de 2 a 5 ha em 54 e 34 municípios; em contrapartida, apenas 32 e 23 municípios apresentaram cultivos em áreas maiores de 20 ha.

Verificou-se pela pesquisa de campo, que a videira e a pereira são as únicas frutíferas que apresentam mais de uma espécie botânica sendo cultivada comercialmente.

Em pessegueiro, verificou-se a presença de 1,9 milhão de plantas jovens e adultas, constituindo-se na segunda frutífera temperada mais plantada no Estado de São Paulo. Neste dado, incluiu-se a nectarineira, que equivale a $12 \%$ da persicultura paulista em número de plantas. De todas as fruteiras temperadas, o pessegueiro foi a cultura que mais evo-

TABELA 1 - Totais de propriedades, municípios e regiões de cultivo no Estado de São Paulo, bem como número de plantas e área, por municípios líderes, no cultivo de frutíferas e noz de clima temperado. Instituto Agronômico (IAC), 2002.

\begin{tabular}{|c|c|c|c|c|c|c|}
\hline Frutífera & $\begin{array}{c}\text { Total de } \\
\text { Propriedades }\end{array}$ & $\begin{array}{c}\text { Total de } \\
\text { Municípios }\end{array}$ & $\begin{array}{l}\text { Total de } \\
\text { Regiões }\end{array}$ & Principais Municípios & $\begin{array}{c}\text { Plantas } \\
\left(\mathrm{n}^{\circ}\right)\end{array}$ & $\begin{array}{l}\text { Área } \\
\text { (ha) }\end{array}$ \\
\hline Ameixeira & 342 & 87 & 20 & $\begin{array}{c}\text { Paranapanema } \\
\text { Angatuba }\end{array}$ & $\begin{array}{l}41.175 \\
40.500\end{array}$ & $\begin{array}{c}125,8 \\
-\end{array}$ \\
\hline Caquizeiro & 1.559 & 171 & 33 & $\begin{array}{c}\text { Mogi das Cruzes } \\
\text { Piedade }\end{array}$ & $\begin{array}{c}217.386 \\
48.521\end{array}$ & $\begin{array}{c}1.232,2 \\
215,9\end{array}$ \\
\hline Figueira & 261 & 70 & 25 & $\begin{array}{l}\text { Valinhos } \\
\text { Campinas }\end{array}$ & $\begin{array}{l}518.735 \\
110.505\end{array}$ & $\begin{array}{l}284,7 \\
122,5\end{array}$ \\
\hline Macieira & 69 & 41 & 17 & $\begin{array}{l}\text { Paranapanema } \\
\text { Taquarivaí }\end{array}$ & $\begin{array}{l}98.845 \\
57.098\end{array}$ & $\begin{array}{c}72,0 \\
-\end{array}$ \\
\hline Nectarineira & 192 & 52 & 18 & $\begin{array}{l}\text { Paranapanema } \\
\text { Guapiara }\end{array}$ & $\begin{array}{l}84.937 \\
18.190\end{array}$ & $\begin{array}{c}188,5 \\
35,9\end{array}$ \\
\hline $\begin{array}{l}\text { Nogueira- } \\
\text { macadâmia }\end{array}$ & 199 & 128 & 39 & $\begin{array}{c}\text { Dois Córregos } \\
\text { Avaré }\end{array}$ & $\begin{array}{l}105.000 \\
56.500\end{array}$ & $\begin{array}{l}332,1 \\
159,0\end{array}$ \\
\hline Nespereira & 250 & 27 & 11 & $\begin{array}{l}\text { Mogi das Cruzes } \\
\text { São Miguel Arcanjo }\end{array}$ & $\begin{array}{c}66.255 \\
6.170\end{array}$ & $\begin{array}{l}204,2 \\
22,3\end{array}$ \\
\hline Pereira & 316 & 97 & 31 & $\begin{array}{c}\text { Narandiba } \\
\text { Presidente Prudente }\end{array}$ & $\begin{array}{l}31.800 \\
11.245\end{array}$ & $\begin{array}{l}27,6 \\
37,3\end{array}$ \\
\hline Pessegueiro & 1.222 & 172 & 35 & $\begin{array}{c}\text { Guapiara } \\
\text { Atibaia }\end{array}$ & $\begin{array}{l}428.597 \\
250.815\end{array}$ & $\begin{array}{l}669,6 \\
215,2\end{array}$ \\
\hline Videira Rústica & 2.428 & 187 & 38 & $\begin{array}{c}\text { Jundiaí } \\
\text { Indaiatuba }\end{array}$ & $\begin{array}{l}9.980 .980 \\
5.491 .500\end{array}$ & $\begin{array}{l}1.933,2 \\
1.135,9\end{array}$ \\
\hline Videira Fina & 2.714 & 237 & 38 & $\begin{array}{l}\text { São Miguel Arcanjo } \\
\text { Pilar do Sul }\end{array}$ & $\begin{array}{l}953.311 \\
344.537\end{array}$ & $\begin{array}{c}1.185,9 \\
579,5\end{array}$ \\
\hline
\end{tabular}


TABELA 2 - Cultivares comerciais de frutíferas e nozes de clima temperado do Estado de São Paulo, citadas acima de 50\% nas pesquisas de opinião com fruticultores. IAC, 2002.

$\begin{array}{ll}\text { Frutífera } & \text { Principais cultivares em ordem } \\ \text { alfabética }\end{array}$

FIGURA 1 - Polos de cultivos das principais fruteiras e nozes de clima temperado no Estado de São Paulo.

luiu em termos de plantas cultivadas; comparando os dados disponibilizados em 1982, verifica-se crescimento de cerca de $420 \%$ (Programa Integrado de Pesquisa, 1985). Em Guapiara, na região de Itapeva, se encontra o principal polo de cultivo do pessegueiro. Já para nectarineira, Paranapanema é o principal município produtor, seguido por Guapiara. Cultivares pouco mais exigentes em frio foram bastante citadas no Sudoeste, região de Itapeva. Tratam-se de introduções do Rio Grande do Sul (Embrapa - Clima Temperado), como: 'Coral', 'Marli', 'Diamante', 'Premier', 'Chimarrita', 'Eldorado', 'Maciel' e 'Granada' e da Universidade da Flórida (UFL): 'Sunripe', 'Rubro-sol', 'Colombina', 'Sunblaze', Fla 84-16N e Fla 84$13 \mathrm{~N}$. As cultivares lançadas pelo Instituto Agronômico (IAC), de baixa exigência em frio, foram mencionadas principalmente pelos persicultores das regiões de Itapetininga, Avaré, Itapeva, Campinas e Bragança Paulista. São elas: séries Aurora, Dourado, Ouromel, Doçura e Jóia, além de 'Biuti', 'Douradão' e da nectarina 'Centenária'. Na cultura, as cultivares com fenótipos assemelhados são geralmente agrupadas por tipos como, por exemplo: 'Aurora-1 e 2', 'Jóia-1, 2, 3, 4 e 5' e outras. Segundo Maia et al. (1996), as cultivares 'Flordaprince' e as dos tipos Aurora e Dourado eram as responsáveis, na década passada, por $15 \%, 30 \%$ e $20 \%$ da persicultura paulista. 'Flordaprince', pêssego introduzido da UFL, foi citado em todas as regiões persícolas. Ressaltou-se na pesquisa o município de Barretos, ao norte do Estado, que se apresentou como a sexta maior área persícola paulista, com 19,5 mil plantas em 93 ha. Para as cultivares citadas na pesquisa, verificam-se safras entre agosto e janeiro, com ciclo de desenvolvimento dos frutos desde 80 até 180 dias (Barbosa et al., 1990a).

A figueira é a terceira frutífera mais cultivada, sendo 'Roxo de Valinhos' a única cultivar comercial; seus frutos amadurecem, normalmente, desde dezembro até abril (Ojima et al, 1998). Com 835 mil plantas, em área de 642 ha, a ficicultura está presente em 70 municípios paulistas, distribuídos em 25 regionais agrícolas (Tabela 1). A figueira, nos moldes da videira e macieira, comporta um maior número de indivíduos por área devido à adoção de pequenos espaçamentos de plantio. Em Valinhos, na região de Campinas, encontra-se o principal pólo, embora haja tendência de migração da cultura mais para o interior do Estado. Devido a problemas diversos, a cultura da figueira foi reduzida em cerca de $60 \%$, quanto ao número de plantas cultivadas. Na década de 80 havia cerca de 2.200 mil plantas, produzindo 31 mil toneladas de figos (Programa Paulista de Fruticultura de Clima Temperado, 1983).

O caquizeiro constituiu-se na quarta frutífera temperada mais plantada, com 740 mil plantas em 4.372 ha de 1.559 propriedades rurais (Tabela 1). Comparando os dados estatísticos das décadas de 70, 80 e 90, verifica-se que o caqui foi uma das culturas que se manteve mais estável quanto ao número total de plantas cultivadas no Estado (Programa Paulista de Fruticultura de Clima Temperado, 1983; Programa Integrado de Pesquisa, 1985). As cultivares mais citadas foram: 'Rama Forte' e 'Giombô' (variáveis), 'Taubaté' (taninosa) e 'Fuyu' e 'Fuyuhana' (doces). Em menor escala, verificou-se o cultivo de 'Jirô', 'Kioto' e 'Tokyogosho'. A colheita dessas cultivares ocorre desde janeiro até maio, dependendo da região de cultivo (Ojima et al., 1998).

Na cultura da macieira, verificou-se a existência de 391 mil plantas cultivadas em 450 ha, representando a quinta frutífera temperada em quantidade de indivíduos. Paranapanema, na região de Avaré, é o maior município produtor, seguido de Taquarivaí (Tabela 1). As principais cultivares citadas foram: 'Anna', 'Brasil', 'Dorset Golden', 'Malus 4', 'Princesa' e 'Rainha', cujas safras ocorrem entre dezembro e março (Campo Dall' Orto et al., 1998). Em menor quantidade foram observados cultivos de 'Gala' e 'Fuji', mais exigentes em frio para quebra-da-endodormência das gemas. Acredita-se que, atualmente, a quantidade de macieiras tenha sido bastante reduzida, devido à eliminação de inúmeros pomares velhos e a pouca renovação varietal. A carência de cultivares mais rústicas e bem adaptadas ao clima, vêm desestimulando os pomicultores paulistas a investirem na cultura da macieira em larga escala comercial, além, é claro, da competição com a região sul do Brasil. Em 1983, estimava-se uma área de 3.250 ha sendo cultivada com macieira, representando $15 \%$ do total nacional (Penteado, 1986). Analizando os dados estatísticos, apresentados há 20 anos (Programa Integrado de Pesquisa, 1985), constata-se que a macieira foi a cultura de clima temperado que mais sofreu redução de área e de número de plantas cultivadas, em cerca de $90 \%$.

Com 291 mil indivíduos plantados em 886 ha, a ameixeira é a sexta frutífera mais cultivada (Tabela 1). Em termos regionais, Itapetininga é o seu maior polo de cultivo, onde há mais de 50\% do total de plantas cultivadas no Estado. 'Reubennel', 'Harry Pickstone' e 'Gulfblaze' introduzidos, respectivamente, da África do Sul e da UFL (Barbosa et al., 1997a), além de 'Gema-de-Ouro', foram as cultivares mais citadas na pesquisa de campo. Afora estas quatro, outras ameixeiras foram relatadas: 'Carmesim', 'Grancuore' e 'Januária', do IAC, além de 'Roxa de Itaquera' e 'Irati', cultivares de seleção local e introduzidos do Instituto Agronômico do Paraná (IAPAR), respectivamente. 'Kelsey Paulista', uma das principais cultivares responsáveis pela expansão da cultura no planalto paulista (Franco et al., 1986), não foi citada em nenhum cultivo comercial. O pico de colheita das ameixas citadas se dá em dezembro e janeiro (Ojima et al., 1998), embora haja cultivares que conseguem produzir frutos em épocas extemporâneas.

A pereira representou a sétima frutífera de clima temperado mais cultivada no território paulista. Com 164 mil plantas cultivadas em 411 ha, a cultura está presente em 43 municípios de 31 regionais agrícolas. $\mathrm{O}$ município com maior concentração de plantas cultivadas é Narandiba, região de Presidente Prudente (Tabela 1). As principais cultivares relata- 
das foram: européias - 'Pêra D’Água', 'Schmidt' ('Smith') e 'Packham's Triumph' (P. communis L.); asiáticas - 'Okusankichi', 'Kosui', 'Hosui' e 'Atago' (P. serotina Rehder), estas últimas nas regiões de Presidente Prudente e Sorocaba. Ainda foram registradas 'Kieffer' (P. communis L. x $P$. serotina Reidher) e as cultivares do IAC, como: 'Primorosa', 'Centenária', 'Seleta', 'Tenra' e 'Triunfo' (P. communis L.), que mesmo sendo de boa qualidade organoléptica, estão presentes apenas em pequenos cultivos. Outras espécies botânicas encontradas foram: P. calleryana Decne. (cv. Taiwan Nashi-C), P. betulaefolia Bunge (cv. Manshu Mamenahi), como porta-enxertos e $P$. bretschneideri Reidher (cv. Ya-li), como copa. A colheita da pêra inicia-se em dezembro e persiste até abril, quando amadurecem as cultivares de origem asiática (Barbosa et al., 1998).

A nespereira constituiu-se na oitava frutífera mais plantada, sendo Mogi das Cruzes o principal polo de cultivo, com 66 mil indivíduos em 204 ha. Esta frutífera foi encontrada em 27 municípios, de 11 regiões paulistas, com 147 mil plantas cultivadas em 381 ha (Tabela 1). Nos últimos 20 anos, o número de plantas cultivadas diminuiu em cerca de 35\% (Programa Integrado de Pesquisa, 1985). Seus principais cultivares são: 'Mizuho', 'Precoce de Itaquera' (Fukuhara) e 'Precoce de Campinas'. Também foram relatados cultivos de 'Centenária', 'Mizumo', 'Mizauto', 'Parmogi' e 'Nectar de Cristal', porém em menor quantidade. O período de safra da nêspera é bastante extenso, normalmente de abril a outubro (Ojima et al., 1998).

O quivizeiro, com 60,4 mil plantas cultivadas em 426 ha, representou a nona frutífera mais cultivada em termos de número de indivíduos. As principais cultivares: Bruno, Monty e Abbott, cujas colheitas ocorrem em abril e maio (Nucci \& Trani, 1998), são encontradas em 28 municípios de 16 regiões. Os dados do LUPA indicam Borborema, região de Jaboticabal, com 22,5 mil plantas, como o principal município de cultivo.

O marmeleiro, com somente 1.140 plantas cultivadas em 4,3 ha, tem como principal cultivar o tipo 'Portugal'. Tietê e Vargem Grande do Sul são os principais municípios produtores de marmelo. Mesmo com as diversas pesquisas desenvolvidas, a cultura do marmeleiro não avançou no Estado de São Paulo. Isso provavelmente tenha ocorrido devido a problemas fitossanitários que impedem o desenvolvimento normal da planta e a produção de frutos de alta qualidade (Campo Dall'Orto et al., 1986).

A macadâmia, por sua vez, contituiu-se na principal nogueira de clima temperado-subtropical cultivada no Estado de São Paulo. Em área de 2.166 ha são cultivadas 587 mil plantas, num total de 199 propriedades. Dois Córregos, região de Jaú, é o principal município produtor (Tabela 1). Em seguida estão classificados os municípios de Bauru, Avaré e São Sebastião da Grama que, juntos, correspondem a $45 \%$ da área cultivada com essa nogueira no Estado. Segundo a Associação dos Produtores de Macadâmia de São Paulo (1993), havia no início da década de 90, cerca de 370 mil nogueiras-macadâmia sendo cultivadas em 2.065 ha, representando $38 \%$ da área nacional. As cultivares mais citadas e que são colhidas de março a maio (Ojima et al., 1998) foram: 'Keauhou', 'Keaau', 'Kau' e 'Mauka', introduzidas do Havaí, 'Keaumi', 'Keaudo' e 'Campinas-B', desenvolvidas pelo IAC e 'Aloha', obtida pela Dierberger Agrícola.

\section{REFERÊNCIASBIBLIOGRÁFICAS}

ASSOCIAÇÃO dos Produtores de Macadâmia do Estado de São Paulo. Levantamento de área plantada com nogueira-macadâmia no Brasil. Dois Córregos: APMESP, 1993. 9p. (Boletim Informativo, 7).

BARBOSA, W.; OJIMA, M.; CAMPO-DALL'ORTO, F. A.; MARTINS, F. P. Época e ciclo de maturação de pêssegos e nectarinas no Estado de São Paulo. Bragantia, Campinas, v.49, n.2, p.221-226, 1990a.

BARBOSA, W.; CAMPO-DALL'ORTO, F. A.; OJIMA, M.; SAMPAIO, V. R. ; BANDEL, G. Ecofisiologia do desenvolvimento vegetativo e reprodutivo do pessegueiro em região subtropical. Campinas: Instituto Agronômico, 1990b. 37p. (Documentos IAC, 17).

BARBOSA, W.; OJIMA, M.; CAMPO-DALL'ORTO, F. A.; CASTRO, J. L.; SANTOS, R. R.; MARTINS, F. P. Avaliação pomológica de germoplasma de ameixa introduzido da Universidade da Flórida, EUA. In: SIMPÓSIO LATINO-AMERICANO DE RECURSOS GENÉTICOS VEGETAIS, 1., 1997a. Campinas. Anais... Campinas: IAC, 1997a.p.59.

BARBOSA, W.; OJIMA, M.; CAMPO-DALL'ORTO, F.A.; RIGITANO, O.; MARTINS, F.P.; SANTOS, R.R.; CASTRO, J. L. Melhoramento do pessegueiro para regiões de clima subtropical-temperado: realizações do Instituto Agronômico no período de 1950-1990. Campinas: Instituto Agronômico, 1997b. 22p. (Documentos IAC, 52).

BARBOSA, W.; CAMPO DALL'ORTO, F.A. ; OJIMA, M.; RIGITANO, O.; MARTINS, F.P.; SANTOS, R.R.; CASTRO, J.L.; SABINO, J.C. Pêra. In: FAHL, et al. (Ed.) Instruções agrícolas para as principais culturas econômicas. Campinas: Instituto Agronômico, 1998. p. 153154. (Boletim, 200).

CAMPODALL'ORTO, F.A.; OJIMA, M.; BARBOSA, W.; SABINO, J..C.; VEIGA, A.A.; RIGITANO, O. Cultivo de marmeleiros em alta densidade de plantio. In: CONGRESSO BRASILEIRO DE FRUTICULTURA, 8., 1986, Salvador.Anais... Salvador: SBF, 1986. v.2, p.409-415.

CAMPO DALL'ORTO, F.A.; OJIMA, M.; BARBOSA, W. RIGITANO, O.; MARTINS, F.P.; SANTOS, R.R.; CASTRO, J.L.; SABINO, J.C. Maçã. In: FAHL et al. (Ed.). Instruções agrícolas para as principais culturas econômicas Campinas: Instituto Agronômico, 1998. p.132134 (Boletim, 200).

FRANCO, J. A. M.; PENTEADO, S. R.; JUNQUEIRA, W. R. Cultura da ameixeira. In: PENTEADO, S. R. (Ed.) Fruticultura de clima temperado em São Paulo. Campinas: Fundação Cargill, 1986. p.95-112.

MAIA, M. L.; AMARO, A. A.; GONÇALVES, J. S.; SOUZA, S. A. M. Produção e mercado de pêra e pêssego no Brasil. Informações Econômicas, São Paulo, v.26, n.2, p.33-48, 1996.

NUCCI, T. A.; TRANI, P. E. Kiwi. In: FAHL et al. (Ed.) Instruções agrícolas para as principais culturas econômicas. Campinas: Instituto Agronômico, 1998. p.127-129 (Boletim, 200).

OJIMA, M.; CAMPO-DALL'ORTO, F. A.; BARBOSA, W.; RIGITANO, $O$. Desenvolvimento da fruticultura de clima temperado em São Paulo. Contribuição do Instituto Agronômico até seu centenário (1887-1987). Campinas: Instituto Agronômico, 1988. 63p. (Documentos IAC, 11).

OJIMA, M.; CAMPO DALL'ORTO, F.A.; BARBOSA, W.; RIGITANO, O.; MARTINS, F.P.; SANTOS, R.R.; CASTRO, J.L.; SABINO, J.C. Pêssego, nectarina, ameixa, caqui, nêspera, nogueira-macadâmia, figo. In: FAHL et al. (Ed.) Instruções agrícolas para as principais culturas econômicas. Campinas: Instituto Agronômico, 1998. p.98155. (Boletim, 200).

PEDRO JUNIOR, M. J.; ORTOLANI, A. A.; RIGITANO, O.; ALFONSI, R. R.; PINTO, H. S.; BRUNINI, O. Estimativa de horas de frio abaixo de 7 e de $13^{\circ} \mathrm{C}$ para regionalização da fruticultura de clima temperado no Estado de São Paulo. Bragantia, Campinas, v.38, p.123-130, 1979.

PENTEADO, S. R. A Cultura da macieira. In: PENTEADO, S. R. (Ed.) Fruticultura de clima temperado em São Paulo. Campinas: Fundação Cargill, 1986. p.9-52

PINO, F. A.; FRANCISCO, V. L. .F. S.; TORRES, A. J.; LORENA NETO, B.; CASER, D. V.; BIRAL, M. A. M. (Org.) Levantamento Censitário de Unidades de Produção Agrícola do Estado de São Paulo. São Paulo: IEA, CATI, SAA, 1997. 4v.

POMMER, C. V. Uva. In: FURLANI, A. M. C. F.; VIEGAS, C. P. (Ed.) O melhoramento de plantas do Instituto Agronômico. Campinas: Instituto Agronômico, 1993. p489-524.

POMMER, C. V.; PIRES, E. J. P.; TERRA, M. M.; PASSOS, I. R. S.; RIBEIRO, I. J. A. Uvas. In: FAHL et al. (Ed.) Instruções agrícolas para as principais culturas econômicas. Campinas: Instituto Agronômico, 1998. p.158-162. (Boletim, 200).

RIGITANO, O. Importantes contribuições à fruticultura de clima temperado. O Agronômico, Campinas, v.20, n.11-12, p.1-6, 1968.

PROGRAMA Paulista de Fruticultura de Clima Temperado-PROFRUT. São Paulo: SAA, CPA, IAC, IEA, ITAL, 1983. 96p.

PROGRAMA Integrado de Pesquisa: Frutas de Clima Temperado. São Paulo: SAA, CPA, IAC, IEA, ITAL, 1985.31p.

SANTOS NETO, J. R. A. Melhoramento da videira. Bragantia, Campinas, v.14, p.237-267, 1955. 